\title{
YouTube: Physics Friend Not Foe
}

\author{
Physics students use online resources to supplement their in-class \\ instruction and not, as commonly thought, to find the answers to \\ homework questions.
}

By Katherine Wright

$\mathrm{n}$ informal conversations with students, Charles Ruggieri of Rutgers University, New Jersey, noticed a surprising theme: if physics students were stuck on a new concept, they turned to online videos for help rather than to textbooks or professors. Motivated by these discussions, Ruggieri conducted a survey to find out exactly what resources students were using and why. The survey shows that students frequently watch videos on sites such as YouTube and Khan Academy and follow line-by-line solutions to textbook problems on Chegg, with most doing so to supplement in-person teaching and not to cheat on assignments [1]. The results of the study could help inform course designs.

Ruggieri conducted an online survey with students of three introductory physics courses for non-physics majors. The 669 survey participants answered questions related to how often they used different learning resources, including textbooks and YouTube. Follow-up interviews were conducted with 11 randomly chosen students, who were asked questions that delved into how they used different resources, as well as why

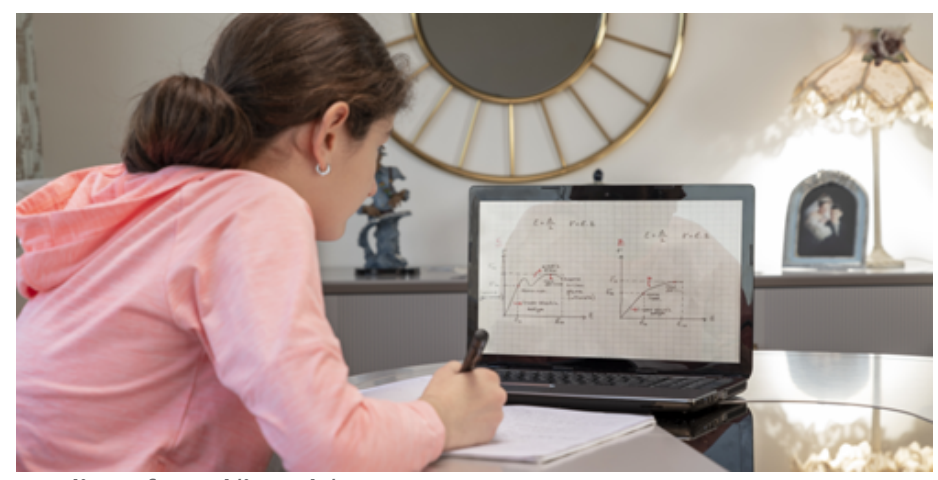

Credit: sefa ozel/iStock/Getty Images they chose one resource over another.

The results show that while all the students turned to online resources, only half of them read course-related textbooks. Online videos and webpages were visited for definitions of concepts that the students didn't understand, for step-by-step guides on how to solve certain problems, or by students seeking to hone physics problem-solving skills by answering additional questions on a topic. Some students did report copying answers from the internet, but those that did recognized that doing so was detrimental to learning, Ruggieri says. Students that did cheat reported only doing so when they had left their homework to the last minute or when they felt that the course materials lacked the information required to tackle the problem.

Katherine Wright is a Senior Editor for Physics.

\section{REFERENCES}

1. C. Ruggieri, "Students' use and perception of textbooks and online resources in introductory physics," Phys. Rev. Phys. Educ. Res. 16, 020123 (2020). 